\title{
CONFIGURAÇÕES DO CORPO NAS PSICOSES
}

M arcia Goidanich

U niversidade Regional Integrada do Alto U ruguai e das M issões (URI) Campus Erechim

RESU M 0: 0 presente artigo propõe uma reflexão sobre algumas particularidades da constituição do corpo nas estruturações psicóticas partindo de um entendimento teórico da psicanálise lacaniana e das proposições de W alter Benjamin. Aponta a psicose como um exemplo privilegiado para pensar as teorizações sobre o corpo despedaçado, na medida em que os sujeitos psicóticos não simbolizam um significante que faça função de suposto saber integrador e permanecem sempre alienados em um desejo não determinado de um outro especular.

PALAVRAS-CH AVE: corpo, psicose, psicanálise, Lacan, Benjamin.

\section{BODY CONFIGURATIONS ON PSYCHOSIS}

ABST RACT: This article proposes a reflection about some peculiarities of the body constitution on psychotic structures according to lacanian psychoanalytical understanding and with W alter Benjamin's propositions. It points out psychosis as a privileged exemple to think about the splited body theorizations, since the psychotic subjects do not symbolise a significant that makes the function of an integrational supposed knowledge and continue always alienated in an indeterminate desire of a specular other.

KEYW ORD S: body, psychosis, psychoanalysis, Lacan, Benjamin. 
Goidanich, M.

"Configurações do corpo nas psicoses"

Louco, sim, louco, porque quis grandeza

Qual a Sorte a não dá.

$\mathrm{N}$ ão coube em mim minha certeza;

Por isso onde 0 areal está

Ficou meu ser que houve, não o que há.

Minha loucura, outros que me a tomem

Com o que nela ia.

Sem a loucura que é o homem

$M$ ais que a besta sadia,

Cadáver adiado que procria?

Fernando Pessoa

0 trabalho com pacientes psicóticos evidencia de imediato a grande multiplicidade subjetiva que este diagnóstico tenta comportar. A experiência clínica revela que as tentativas de generalização ou de padronização sob um mesmo rótulo diagnóstico acabam sendo muito empobrecedoras. Podese dizer que algo similar ocorre também nas demais constituições de diagnósticos, onde as singularidades tendem a ser apagadas ou deixadas de lado para que algum enquadramento generalizador, que enfatiza certo traço comum, seja possível. Tal é, predominantemente, a lógica empregada pelas diversas elaborações científicas que visam construir seus entendimentos teóricos sobre os seres humanos. I mporta destacar, no entanto, que se, por um lado, a constatação de quadros estruturais mais generalistas pode auxiliar de certa forma no trabalho clínico, por outro, ela não deveria ofuscar a riqueza das singularidades subjetivas.

Partindo da obra freudiana, as elaborações psicanalíticas lacanianas parecem caminhar no sentido de caracterizar montagens estruturais que fundamentam a constituição dos sujeitos, valorizando, ao mesmo tempo, a história singular que cada um deles elabora. No trabalho clínico com psicóticos, tais diferenças mostram-se com imensa riqueza. 0 modo como os psicóticos constituem seu corpo e se relacionam com ele pode ser um exemplo das grandes variações que se pode encontrar dentro de um mesmo quadro estrutural amplo. Percebem-se distinções entre o modo de constituição do corpo de 
um paranóico e o de um esquizofrênico, assim como também chama a atenção as alterações que ocorrem no corpo de um mesmo sujeito quando entra em uma crise aguda. Além disso, é preciso levar em conta todas as diferenças particulares de cada sujeito. Fica, assim, evidente que qualquer reflexão sobre o estatuto do corpo nas psicoses será sempre um recorte parcial, mas, ainda assim, acreditase ser interessante constituir uma breve trajetória neste sentido.

U $m$ aspecto que a clínica das psicoses evidencia é a freqüente relação de grande estranhamento que os psicóticos mantêm com seu corpo. O s sujeitos psicóticos parecem estar muitas vezes alheios de seu próprio corpo. Relacionam-se com ele como se fosse um outro, um objeto estranho. Tomam o corpo quase como uma carcaça da qual pudessem prescindir. 0 corpo apresenta-se como uma alteridade que por vezes sugere não fazer questão ao sujeito. Em certos casos, os psicóticos parecem ignorar seu corpo de modo ainda mais enfático, agindo como se ele efetivamente não lhes dissesse respeito. A própria estesis do corpo dos psicóticos parece ficar muitas vezes amortecida. Percebe-se nestes casos um certo anestesiamento do corpo, de tal forma que os sujeitos parecem não estar sujeito à dor, ao frio, ao calor, à fome, ou ao desejo sexual. M esmo as doenças físicas não abalam o organismo dos psicóticos do mesmo modo como ocorre nas neuroses.

Por outro lado, nos momentos de crises, quando acometidos pelo agudo dos surtos, muitas vezes a problemática passa a ser radicalmente distinta. N esses períodos, os sujeitos psicóticos ficam totalmente tomados pelas afecções que sentem atingir seu corpo. São quase esmagados pela enxurrada de estímulos que os aflige e sobre a qual não conseguem ter controle. Escutam vozes, vêem imagens, sentem empurrões, beliscões e puxões que os dominam totalmente. M esmo seu pensamento é muitas vezes controlado por imposições que já não mais podem distinguir se são próprias ou se vêm de um outro. N esses momentos, evidencia-se que não há nenhum tipo de barreira ou censura, nenhum amortecimento para a torrente de sensações produzidas e percebidas pelo sujeito. A alteridade o esmaga, o domina completamente, aniquilando a própria possibilidade de seguir existindo enquanto um sujeito que faz alguma barra frente ao O utro, um sujeito que impõe algum tipo de corte separador. 
Goidanich, M.

"Configurações do corpo nas psicoses"

Jaques Lacan (1999), em seu Seminário de 1957-1958, As Formações do Inconsciente, destaca a suplência, que ocorre na psicose, do 0 utro (maiúsculo) como sede da fala, como simbólico, pelo outro (minúsculo) como similar, como imaginário. A carência de um significante primário que funcione como organizador para toda a estruturação, garantindo algum saber, mesmo que apenas suposto, impossibilita ao psicótico a simbolização necessária para dar sustentação às relações imaginárias. Com isso, Lacan aponta para uma constante transitividade característica do sujeito psicótico. 0 discurso delirante apareceria como o único apelo através do qual o psicótico tenta sustentar em si uma certa intransitividade do sujeito. É a redução do O utro como sede da fala e garantia de verdade ao outro como dual, como sendo sua própria imagem, que causa ao psicótico tantas dificuldades de se manter num real simbólico, num real, diz Lacan, humano (p. 15).

Tal fragilidade, que não é totalmente inexistente nas estruturas neuróticas, fica exacerbada nas psicoses, evidenciando de modo ímpar o decorrente esfacelamento do corpo, sua falta de unidade, seu eterno inacabamento. Se nas neuroses os sujeitos procuram manter uma sustentação, mesmo que em certos momentos precária, partindo de uma suposição de saber, da simbolização de um significante primordial organizador, nas psicoses, a falta de tal suposição e da simbolização de um significante que exerça tal função, põe em maior evidência a transitoriedade das amarras e a fragilização do corpo.

$\mathrm{N}$ ão há como pensar em um corpo humano que não se constitua a partir de um processo de simbolização, a partir da inscrição de marcas deixadas por uma história, pela constante interação com o 0 utro, por recortes do desejo. É a impossibilidade de apropriarse de um corpo com suas marcas singulares, a impossibilidade de percebêlo como formando uma certa unificação, que está exacerbada na psicose. Por não conseguir separar-se, criar alguma barreira em relação ao 0 utro, o psicótico permanece totalmente alienado, invadido por este. Assim, na psicose, o corpo não é uno e nem é próprio, pois segue sendo, muitas vezes, apenas uma parte, um complemento do corpo de um outro especular.

$D$ ito de outro modo, o que se percebe, a partir da experiência clínica com psicóticos e sob a luz das construções teóricas propostas 
por Lacan, é que o que está em jogo na estruturação das psicoses é justamente a forclusão do nome-do-pai, ou seja, a não simbolização de uma metáfora paterna, que possibilita alguma definição para 0 desejo do 0 utro. Compreendendo a função paterna como aquilo que possibilita o corte, como a intervenção necessária de um terceiro para a separação sujeito/O utro primordial, percebe-se que, nas psicoses, o próprio corpo dos sujeitos acaba não sendo constituído, simbolizado, como efetivamente separado do 0 utro. 0 que ocorre, na psicose, é uma falha no processo de simbolização, o qual possibilitaria a passagem de uma relação dual, imaginária, com o pequeno outro, para uma relação mediada por um terceiro, característica, por exemplo, do laço neurótico com o grande 0 utro.

No seminário de 1955-1956, inteiramente dedicado ao estudo das psicoses, Lacan (1992) retoma a questão da constituição do sujeito como sendo sempre totalmente referenciada ao outro. Para Lacan, é o desejo do outro que funciona como referência para toda a constituição de um eu. D iz Lacan:

É que o eu humano é o outro, e que no começo o sujeito está mais próximo da forma do outro do que do surgimento de sua própria tendência. Ele é origi nariamente coleção incoerente de desejos - aí está o verdadeiro sentido da expressão corpo espedaçado - e a priméra síntese do ego é essencialmente alter ego, ela é alienada. 0 sujeito humano desejante se constitui em torno de um centro que é o outro na medida em que ele lhe dá a sua unidade, e o primeiro acesso que ele tem do objeto, é o objeto enquanto objeto do desejo do outro.

(p. 50).

Evidencia-se, a partir dessas observações, que, tanto na neurose como na psicose, o sujeito origina-se a partir de uma alienação no outro. A falta da entrada efetiva de um terceiro, que venha a constituir um corte, constituir o processo de simbolização, é que distingue fundamentalmente a psicose da neurose.

Já em 1936, Lacan realiza uma conferência sobre 0 Estádio do Espelho como Formador da Função do [Eu] tal qual nos é Revelada na Experiência Analítica, texto que vem a ser publicado pela primeira vez apenas em 1949 (publicação sem data). Lacan enfatiza nesse texto que a forma total do corpo, a qual antecede em uma miragem 
Goidanich, M.

"Configurações do corpo nas psicoses"

a maturação de sua potência, vem ao sujeito nascente de uma exterioridade. É o outro que faz papel de espelho, oferecendo uma Gestalt constituinte para aquele corpo que ainda não está constituído. 0 estádio do espelho corresponderia, assim, ao drama da precipitação da insuficiência à antecipação, ou seja, de uma imagem do corpo fragmentado a uma forma ortopédica de sua totalidade. Tal totalidade, que é fundamentalmente alienante, na medida em que vem do outro, vai marcar todo o desenvolvimento mental do sujeito.

0 corpo é descrito por Lacan, então, como corpo fragmentado, que apenas poderá constituir uma integração imaginária a partir de uma necessária alienação, mas também da separação de uma figura primordial. Lacan lembra ainda que esse corpo fragmentado aparece com bastante freqüência nos sonhos. A fragmentação revela-se também com grande evidência nas linhas de fragilização que definem a anatomia fantasmática manifesta nos sintomas de cisão esquizóides. Parece ser justamente nessa paradoxal relação de alienação no outro e separação que incide uma das problemáticas da estruturação das psicoses. O u seja, a possibilidade de jogar com a imagem da integração corporal, para a qual é preciso ocorrer a simbolização de um significante paterno que viabilize o processo de separação do outro, é que não ocorre nos casos de estruturações psicóticas.

W alter Benjamin (1975 e 1994) trabalha também intensamente a noção do despedaçamento, da falta de unidade do corpo, que tão evidente fica nos casos de psicoses. 0 estudo da questão do corpo a partir das proposições de Benjamin possibilita um interessante diálogo com o entendimento psicanalítico do corpo nas psicoses. Talvez as psicoses possam ser pensadas como um exemplo privilegiado para ilustrar a proposta benjaminiana de teorização sobre 0 corpo, na medida em que põem em evidência, principalmente no momento das crises agudas, um corpo despedaçado, cindido, sem unificação. Benjamin parece apontar que o corpo sem unidade, desmanchado, é característico de todo ser humano. Há na neurose, no entanto, uma tentativa de apagar esse desmantelamento, uma busca de unificação, que ocorre a partir da entrada de um terceiro que sus tenta uma suposição de saber e possibilita a ascensão à simbolização. $\mathrm{N}$ as psicoses, por outro lado, e especialmente nas montagens esquizofrênicas, mesmo uma primordial busca especular de integração 
fracassa. 0 outro não devolve uma imagem integradora e o que se passa é que o sujeito permanece totalmente alienado, absorvido como uma parte deste. Pode-se dizer que as esquizofrenias constituem, assim, o mais vivo exemplo do corpo despedaçado.

Analisando a expressão do corpo tanto nas artes plásticas como na literatura, Benjamin (1994, op. cit.) destaca exemplos nos quais se evidenciam as desfigurações, as distorções. As pinturas de Francis Bacon e a obra literária de K afka são apontadas como fontes ricas para se pensar o corpo como disforme, inerentemente dividido, não unificável e totalmente marcado pelas pressões da cultura. 0 mundo pesa sobre os sujeitos impondo seu tempo, seu andamento, seu modo de funcionar, e, com isso, marca o corpo, configurando gestos, velocidades, modos de se comportar.

Benjamin (1975, op. cit.) destaca a necessidade que surge na modernidade dos sujeitos se defenderem frente ao excesso de estímulos que os cercam constantemente. D ecorre disso o estabelecimento de um certo grau constante de anestesiamento. O s sujeitos precisam anestesiar-se na busca de alguma proteção frente a esse excesso. Talvez seja isso que as psicoses podem evidenciar de modo extremado, por exemplo, nas situações de catatonia ou de severa cronificação asilar: um anestesiamento intenso que pode ser pensado tanto como um enclausuramento, um ensimesmamento profundo, ou como uma entrega total, uma desistência de seguir lutando contra a invasão absoluta do outro.

Para Benjamin, segundo Perrone (inédito), a singularidade do indivíduo efetivamente se revela na sua solidão e finitude. $N$ ão é da figura harmoniosa, totalizante, que pressupõe a bela forma que Benjamin refere ser possível extrair a significação dos sujeitos, mas, inversamente, ele afirma que essas significações partem das ruínas do corpo, da carne dilacerada. Benjamin defende, assim, a dissolução do um, do unificado, para potencializar o múltiplo. Partindo da fissura, da desconstrução do corpo, Benjamin enfatiza a transitoriedade do sujeito e luta para sustentá-la. 0 projeto benjaminiano se caracterizaría pela construção de um novo corpo, que não estaria submetido ao engano da unificação e seria, assim, um corpo de resistência.

Acompanhando os passos dessas elaborações benjaminianas, desponta neste momento uma questão: seria o corpo nas psicoses 
Goidanich, M.

"Configurações do corpo nas psicoses"

um corpo de resistência, na medida em que evidencia 0 despedaçamento? $\mathrm{O}$ u seria ele justamente um corpo no qual a resistência não pôde fazer função, não pôde se inscrever, deixando-o totalmente tomado, totalmente a mercê do outro? 0 que caracterizaria a possibilidade de alguma diferenciação, de alguma força resistencial? N ão seria justamente o jogo que ocorre entre esses dois processos, o de separação e o de perda na alteridade, jogo este que, por mais paradoxal que pareça, justamente sempre se dá de modo consonante, constituindo um constante devir onde separação e alienação fundam-se concomitantemente, possibilitam-se de modo simultâneo, que fundaria a inscrição de uma marca de diferença, de resistência, de algo novo?

Parece ser justamente esse jogo de sincronicidade da relação entre dentro e fora, entre eu e outro, que pode ser percebido e simbolizado nas estruturações neuróticas, que, nas psicoses, sofre uma cisão. Parece ser, enfim, o rompimento no desenrolar simultâneo do processo de alienação e separação, processo este que é fundamental para viabilizar toda constituição subjetiva e, consequentemente, a estruturação corporal, que está em jogo nas psicoses. É justamente nesse processo de constituição do enlaçamento sujeito/O utro que a clínica psicanalítica das psicoses precisaria tentar intervir.

\section{REFERÊNCIAS}

BEN JAM IN, W. Sobre Alguns Temas em Baudelaire. In: Textos Escolhidos. São Paulo: Abril Cultural, 1975. (O s Pensadores; v. 48).

BEN JAM IN, W. Franz Kafka. A propósito do décimo aniversário de sua morte. In: M agia e técnica, arte e política: ensaios sobre literatura e história da cultura. São Paulo: Brasiliense, 1994.

LACAN , J. O Seminário. Livro III. As Psicoses (1955-1956) Rio de Janeiro: Zahar, 1992.

LACAN , J. 0 Seminário. Livro V. As Formações do Inconsciente (19571958) Rio de Janeiro: Zahar, 1999. 
LACAN , J. O Estádio do Espelho como Formador da Função do [Eu] tal qual ela nos é Revelada na Experiência Psicanalítica (1948/1949). In: Cadernos Lacan. 1à Parte. Publicação não-comercial. D ocumento Interno da Associação Psicanalítica de Porto Alegre. Sem data.

PERRONE, C. U m olhar capturado pela intensidade. 0 corpo e Walter Benjamin. Porto Alegre. Inédito.

M arcia G oidanich épsi cóloga, especialista em atendimento dínico com ênfaseem psicanálise pela clínica deatendimento psicológi co da U FRGS. M estranda do Programa dePósG raduação em Psicologia Social el nstitucional da U FRGS. Professora da U niversidade Regional Integrada do Alto U ruguai edasM issões (U RI)-C ampusErechim-RS. Psicóloga Concursada do M unicípio junto ao Centro de Atenção Psicossocial dePasso Fundo-RS. 0 endereço eletrônico da autora é: goidanich@uol.com.br

$M$ arcia Goidanich

Configurações do corpo nas psicoses.

Recebido: 16/5/2003

1a revisão: 15/07/2003

Aceite final: 9/9/2003 